\title{
Proteasome activity related with the daily physical activity of COPD patients
}

\author{
This article was published in the following Dove Press journal: \\ International Journal of COPD \\ 22 May 2017 \\ Number of times this article has been viewed
}

\author{
Kang-Yun Lee ${ }^{1,2, *}$ \\ Tzu-Tao Chen ${ }^{1, *}$ \\ Ling-Ling Chiang',3 \\ Hsiao-Chi Chuang ${ }^{1,3}$ \\ Po-Hao Feng ${ }^{1,2}$ \\ Wen-Te Liu' ${ }^{1-3}$ \\ Kuan-Yuan Chen' \\ Shu-Chuan Ho $\mathrm{Ho}^{1,3}$ \\ 'Division of Pulmonary Medicine, \\ Department of Internal Medicine, \\ Shuang Ho Hospital, Taipei Medical \\ University, New Taipei City, ${ }^{2}$ Division \\ of Pulmonary Medicine, Department \\ of Internal Medicine, School of \\ Medicine, College of Medicine, \\ Taipei Medical University, ${ }^{3}$ School \\ of Respiratory Therapy, College of \\ Medicine, Taipei Medical University, \\ Taipei, Taiwan \\ *These authors contributed equally \\ to this work
}

Background: COPD is a debilitating disease that affects patients' daily lives. One's daily physical activity (DPA) decreases due to multifactorial causes, and this decrease is correlated with a poor prognosis in COPD patients. Muscle wasting may at least be partly due to increased activity of the ubiquitin proteasome pathway and apoptosis.

Methods: This study investigated the relationships among DPA, circulating proteasome activity, and protein carbonyl in COPD patients and healthy subjects (HSs). This study included 57 participants (42 patients and 15 healthy subjects). Ambulatory DPA was measured using actigraphy, and oxygen saturation was measured with a pulse oximeter.

Results: COPD patients had lower DPA, lower 6 min walking distance (6MWD), lower delta saturation pulse oxygenation $\left(\mathrm{SpO}_{2}\right)$ during the 6MWT, and lower delta $\mathrm{SpO}_{2}$ during DPA than HSs. COPD patients had higher proteasome activity and protein carbonyl than HSs. Circulating proteasome activity was significantly negatively correlated with DPA $(r=-0.568, P<0.05)$ in COPD patients, whereas delta $\mathrm{SpO}_{2}$ during the $6 \mathrm{MWT}$ was significantly positively correlated with proteasome activity $(r=0.685, P<0.05)$ in HSs. Protein carbonyl was significantly negatively correlated with the body mass index $(r=-0.318, P<0.05)$, mid-arm circumference $(r=0.350$, $P<0.05$ ), calf circumference ( $r=0.322, P<0.05$ ), forced expiratory volume in the first second $(r=-0.441, P<0.01)$, and 6MWD $(r=-0.313, P<0.05)$ in COPD patients. Our results showed no significant difference in inflammatory markers (interleukin- 6 and tumor necrosis factor- $\alpha$ ) or ubiquitin between the two groups.

Conclusion: COPD patients had lower DPA levels and higher circulating proteasome activity than HSs, and a negative correlation of DPA with circulating proteasome activity.

Keywords: chronic obstructive pulmonary disease, circulating proteasome, daily physical activity, protein carbonyl, anthropometric indicator

\section{Background}

COPD patients have pathology involving both the lungs and extrapulmonary abnormalities such as skeletal muscle wasting, cachexia, diabetes, and anemia. ${ }^{1}$ The mechanistic basis underlying COPD is complex and can involve recurrent inflammation, oxidative stress, a protease/antiprotease imbalance, environmental results, and host genetics. ${ }^{2}$

Muscle weakness, from atrophy and intrinsic metabolic abnormalities, ${ }^{3}$ and a reduced exercise capacity are associated with increased mortality in COPD patients, independent of the severity of airflow obstruction. ${ }^{4}$ Atrophy is mostly attributed to increased protein degradation, and the ubiquitin-proteasome pathway is involved in limb atrophy. Proteasomes regulate important intracellular functions ${ }^{5}$ by degrading intracellular proteins. Lower limb muscle atrophy is relatively common in persons with COPD. Calf circumference (CC) is highly associated with exercise tolerance, and it might be of value in predicting exercise intolerance in COPD patients. ${ }^{6}$ Patients
Correspondence: Shu-Chuan Ho School of Respiratory Therapy, College of Medicine, Taipei Medical University, $250 \mathrm{Wu}$-Xing St, Taipei I I03 I, Taiwan Tel +886 22736 I66I ext 35I2 Fax +886 22739 I | 43 Email shu-chuan@tmu.edu.tw (c) (1) (5) 2017 Lee et al. This work is published and licensed by Dove Medical Press Limited. The full terms of this license are available at https://www.dovepress.com/terms.php
and incorporate the Creative Commons Attribution - Non Commercial (unported, v3.0) License (http://creativecommons.org/licenses/by-nc/3.0/). By accessing the work you

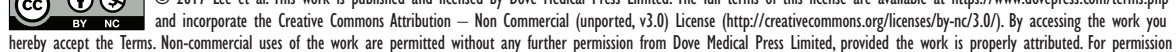
for commercial use of this work, please see paragraphs 4.2 and 5 of our Terms (https://www.dovepress.com/terms.php). 
with severe COPD and hypoxemia exhibit greater levels of oxidative stress in their limb muscles, both at rest and after exercise, while showing a poorer quadriceps performance compared to healthy controls. ${ }^{7}$

Physical activity is defined as any bodily movement produced by skeletal muscles that substantially increases energy expenditure. ${ }^{8,9}$ Low levels of physical activity are associated with systemic inflammation, left cardiac dysfunction, ${ }^{10}$ low bone mineral density, ${ }^{11}$ lung function decline, hospitalization, and mortality. ${ }^{12}$ COPD is a debilitating disease affecting patients' daily lives. ${ }^{11}$ The etiology of reduced daily physical activity (DPA) in COPD patients is multifactorial. ${ }^{13}$ A sedentary lifestyle, severe COPD, severity of dyspnea, dynamic hyperinflation, ${ }^{14}$ worse leg muscle function, longterm oxygen therapy, and extrapulmonary effects of COPD ${ }^{10}$ were independently associated with lower physical activity. ${ }^{15}$ It is not known if any relationship of proteasomes exists with oxidative stress that develops during DPAs and the functional exercise capacity of patients with COPD. The objectives of this study were to analyze the contributions of DPA, exercise capacity (assessed by the 6 min walking distance [6MWD]), oxidative stress, and systemic inflammation to the circulating proteasome concentration of patients with COPD.

\section{Methods}

\section{Study design and patients}

We conducted a cross-sectional study in persons who were recruited from the pulmonary outpatient unit of a medical center and healthy volunteers. A diagnosis of COPD was based on the Global Initiative for Chronic Obstructive Lung Disease guidelines. ${ }^{16}$ Those with an acute infection or acute exacerbation were excluded. In total, 42 patients and 15 healthy subjects (HSs) were qualified and agreed to participate. All participants had similar physical activity patterns during weekdays or weekends and were in a stable condition, and COPD patients were undergoing standard pharmacologic treatment. The study protocol was approved by the Ethics Committee of the Taipei Medical UniversityJoint Institutional Review Board, and all subjects provided written informed consent before taking part in the study.

\section{Procedures and measurements}

Participants were interviewed by well-trained researchers to collect demographic, lifestyle, and disease-related data. Participants' weight, height, body fat (\%), mid-arm circumference (MAC), and CC were measured, and the physical function capacity was evaluated by a well-trained therapist with the 6MWT and pulmonary function tests. Weight, height, MAC, and CC were measured according to standard methods. The body mass index (BMI) was calculated as the weight divided by the height squared $\left(\mathrm{kg} / \mathrm{m}^{2}\right)$. A bioelectrical impedance analysis (TANITA, BF-800 Body Fat Monitor; Tanita, Tokyo, Japan) was performed to determine the percentage body fat. The fat-free mass was calculated from the body weight minus the fat mass. The fat-free mass index was calculated as the fat-free mass $(\mathrm{kg}) /$ height $(\mathrm{m}) .{ }^{17}$

Enzyme-linked immunosorbent assays were used to determine the plasma levels of interleukin (IL)-6 (eBioscience, San Diego, CA, USA), tumor necrosis factor (TNF)- $\alpha$ (eBioscience), protein carbonyl (Cell Biolabs, San Diego, CA, USA), ubiquitin (Mybiosource, San Diego, CA, USA), and proteasome activity (Biovision, Milpitas, CA, USA), according to the manufacturers' instructions.

Pulmonary function parameters were assessed using the Vitalograph Spirotac VTM after a 10 min rest; the postbronchodilator forced expiratory volume in the first second $\left(\mathrm{FEV}_{1}\right)$ and forced vital capacity (FVC) were measured, and the $\mathrm{FEV}_{1} / \mathrm{FVC}$ ratio was calculated. All included COPD patients had an $\mathrm{FEV}_{1} / \mathrm{FVC}$ ratio of $<70 \%$.

The exercise capacity was assessed with the 6MWT, according to American Thoracic Society (ATS) guidelines. All subjects were instructed to walk as far as possible, but were allowed to stop and rest during the test. ${ }^{18}$ Oxygen saturation was recorded using a continuous finger-adapted pulse oximeter.

Oxygen saturation was measured during DPA; we monitored oxygenation with an oximeter (WristOx; Nonin Medical, Plymouth, MN, USA) and daily activity using a Micro-Mini Motionlogger ${ }^{\circledR}$ Actigraph (MM; Ambulatory Monitoring Inc., Ardsley, New York, USA). Each patient underwent an ambulatory recording that produced $24 \mathrm{~h}$ of continuous data and a daily-card record. DPA refers to the amount of activities excluding sleep time. We used a desaturation index or percent time for oxygen saturation, which was $<90 \%$ during the recording. ${ }^{19}$

\section{Statistical analysis}

Results were statistically analyzed with SPSS for Windows 19.0 (IBM Corporation, Armonk, NY, USA) and the program GraphPad Prism 5 (GraphPad Software, La Jolla, CA, USA). Descriptive data are expressed as the mean \pm standard deviation (SD). Continuous variables were compared using Student's $t$-test, and categorical variables were compared between the two groups using a chi-squared test. Pearson's correlation was used to evaluate the strength of the relationship between the ubiquitin-proteasome system 
and DPA indicators measured with the actigraph. Statistical significance for all evaluations was set at $P<0.05$.

\section{Results}

\section{Baseline characteristics}

Descriptive statistics for the variables studied are shown in Table 1. Mean ages were similar in HSs and COPD subjects (64.1 \pm 11.7 vs $67.1 \pm 6.5$ years, $P>0.05$ ). Anthropometric data for HSs and patients with COPD did not differ significantly. Most COPD patients had a smoking history (92.8\%), and they averaged $36.5 \pm 23.6$ pack-years. As expected, pulmonary function values were significantly lower in COPD patients than in $\mathrm{HSs}$, and COPD patients were in a severe stage $\left(\mathrm{FEV}_{1}=40.5 \% \pm 16.5 \% ; \mathrm{FEV}_{1} / \mathrm{FVC}=48.7 \% \pm 11.0 \%\right)$.

\section{Decreased DPA in COPD patients}

As shown in Table 1 and Figure 1, the 6MWD (416.3 \pm 11.7 vs $535.1 \pm 14.2 \mathrm{~m}, P<0.01)$ and delta saturation pulse oxygenation $\left(\mathrm{SpO}_{2} ;-11.5 \% \pm 0.9 \% \mathrm{vs}-5.5 \% \pm 0.6 \%, P<0.01\right)$ were lower in COPD patients than in HSs; the actigraphic record

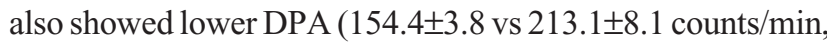

Table I Characteristics of the 57 participants

\begin{tabular}{|c|c|c|c|}
\hline Variables & $\begin{array}{l}\text { Healthy } \\
\text { subjects } \\
(n=I 5)\end{array}$ & $\begin{array}{l}\text { COPD } \\
\text { patients } \\
(n=42)\end{array}$ & $P$-value \\
\hline Age (years), mean $\pm S D$ & $64.10 \pm 11.7$ & $67.1 \pm 6.5$ & 0.113 \\
\hline Gender (M/F) & $12 / 3$ & $39 / 3$ & 0.180 \\
\hline Smoker & & & 0.465 \\
\hline Nonsmoker (\%) & II (73.3) & $3(7.2)$ & \\
\hline Current smoker (\%) & $4(26.7)$ & $9(21.4)$ & \\
\hline Ex-smoker $(\%)$ & 0 & $30(7 \mathrm{I} .4)$ & \\
\hline \multicolumn{4}{|c|}{ Anthropometric indicators, mean $\pm S D$} \\
\hline BMI $\left(\mathrm{kg} / \mathrm{m}^{2}\right)$ & $22.8 \pm 3.0$ & $24.5 \pm 3.4$ & 0.0908 \\
\hline $\operatorname{MAC}(\mathrm{cm})$ & $26.6 \pm 4.2$ & $27.3 \pm 3.1$ & 0.9566 \\
\hline $\mathrm{CC}(\mathrm{cm})$ & $35.5 \pm 2.9$ & $33.1 \pm 5.8$ & 0.8111 \\
\hline FFMI $\left(\mathrm{kg} / \mathrm{m}^{2}\right)$ & $19.5 \pm 6.3$ & $18.0 \pm 0.3$ & 0.1718 \\
\hline \multicolumn{4}{|c|}{ Pulmonary function tests, mean $\pm S D$} \\
\hline $\mathrm{FEV}_{1}(\mathrm{~L} / \mathrm{min})$ & $2.37 \pm 0.53$ & $\mathrm{I} .0 \mathrm{I} \pm 0.46$ & $<0.0001$ \\
\hline $\mathrm{FEV}_{1}(\% \text { predicted })^{\mathrm{a}}$ & $88.3 \pm 7.8$ & $40.5 \pm 16.5$ & $<0.0001$ \\
\hline $\mathrm{FVC}(\mathrm{L} / \mathrm{min})$ & $2.99 \pm 0.66$ & $2.05 \pm 0.62$ & $<0.0001$ \\
\hline FVC (\% predicted) & $89.5 \pm 10.2$ & $63.1 \pm 16.6$ & $<0.0001$ \\
\hline $\mathrm{FEV}_{\mathrm{l}} / \mathrm{FVC}(\%)$ & $80.8 \pm 5.6$ & $48.7 \pm 11.0$ & $<0.000$ I \\
\hline 6MWD (meter) & $535.1 \pm 14.2$ & $416.3 \pm 11.7$ & $<0.0001$ \\
\hline DPA (counts/min) & $213.1 \pm 8.1$ & $154.4 \pm 3.8$ & $<0.0001$ \\
\hline Protein carbonyl & $4.7 \pm 1.1$ & $9.9 \pm 5.4$ & 0.0065 \\
\hline Proteasome activities & $0.3 \pm 0.2$ & $1.1 \pm 0.9$ & 0.0051 \\
\hline
\end{tabular}

Notes: according to FEV , values, $12(28.6 \%)$ subjects had very severe (FEV $<30 \%$ ), $18(42.8 \%)$ subjects had severe $(50 \%<\mathrm{FEV}, \leq 30 \%)$, and $12(28.6 \%)$ subjects had mild to moderate COPD (FEV $\geq 50 \%$ ).

Abbreviations: 6MWD, 6 min walking distance; BMl, body mass index; CC, calf circumference; DPA, daily physical activity; $\mathrm{FEV}_{1}$, forced expiratory volume in the first second; FFMI, fat-free mass index; FVC, forced vital capacity; MAC, mid-arm circumference.
$P<0.01)$ and delta $\mathrm{SpO}_{2}(-15.4 \% \pm 1.4 \%$ vs $-7.4 \% \pm 0.7 \%$, $P<0.01)$ in COPD patients.

Figure 2 shows the all-day activity distribution. Time spent walking by the COPD patients was lower than that of HSs (1.28 \pm 5.36 vs $2.58 \pm 0.31 \mathrm{~h}, P<0.01)$, while their standing time $(3.10 \pm 0.12$ vs $2.36 \pm 0.20 \mathrm{~h}, P<0.01)$ and sitting time $(8.17 \pm 0.22$ vs $6.30 \pm 0.29 \mathrm{~h}, P<0.01)$ were higher than those of HSs and no significant difference was found for lying down time $(8.31 \pm 0.25$ vs $8.29 \pm 0.30 \mathrm{~h}, P>0.05)$. Our results showed that COPD patients had changed their lifestyle, with over 34\% exhibiting a sedentary lifestyle and had reduced their daily activities.

\section{Increased serum oxidative stress and proteasome activity in COPD patients}

Levels of protein carbonyl, IL-6, TNF- $\alpha$, proteasome activity, and ubiquitin in HSs and COPD patients are presented in Figure 3 and Table 1. In COPD patients, serum levels of protein carbonyl $(9.88 \pm 5.36$ vs $4.72 \pm 1.16$ $\mathrm{nmol} / \mathrm{mg}, P<0.01)$ and proteasome activity $(1.14 \pm 0.88$ vs $0.29 \pm 0.21 \mu \mathrm{g} / \mathrm{mL}, P<0.01)$ were higher than those in HSs; no significant difference was seen in the levels of IL-6 (2.78 \pm 1.76 vs $2.07 \pm 0.76 \mathrm{pg} / \mathrm{mL}, P>0.05), \mathrm{TNF}-\alpha(1.21 \pm 0.10$ vs $1.903 \pm 0.39 \mathrm{pg} / \mathrm{mL}, P>0.05)$, or ubiquitin $(0.72 \pm 0.51$ vs $0.83 \pm 0.35 \mathrm{ng} / \mathrm{mL}, P>0.05)$.

\section{Serum proteasomes, not oxidative stress, are associated with decreased DPA}

Table 2 shows the Pearson's correlation coefficients of proteasome activity, protein carbonyl, anthropometric indicators, actigraphic data, the 6MWD, and delta $\mathrm{SpO}_{2}$ during the 6MWT. In all subjects, the MAC, $\mathrm{CC}, \mathrm{FEV}_{1}$, and 6MWD were significantly correlated with carbonyl oxidation ( $r=-0.323, P<0.05 ; r=-0.340, P<0.05 ; r=-0.526, P<0.01$; and $r=-0.439, P<0.05$, respectively), but there was no significant correlation with proteasome activity $(P>0.05)$. Neither the BMI, fat-free mass index, delta $\mathrm{SpO}_{2}$ during DPA, nor the delta $\mathrm{SpO}_{2}$ during 6MWT was significantly correlated with proteasome activity or protein carbonyl (all $P<0.05$ ). DPA was significantly correlated with proteasome activity ( $r=-0.529, P<0.05)$, but not with protein carbonyl ( $r=0.089$, $P>0.05)$. In HSs, no parameters, except delta $\mathrm{SpO}_{2}$ during the 6MWT which was significantly positively correlated with proteasome activity ( $r=0.685, P<0.05)$, were significantly correlated with proteasome activity or protein carbonyl (all $P>0.05$ ). In COPD patients, except DPA which was significantly negatively correlated with proteasome activity ( $r=-0.568, P<0.05)$, no other parameters were significantly 

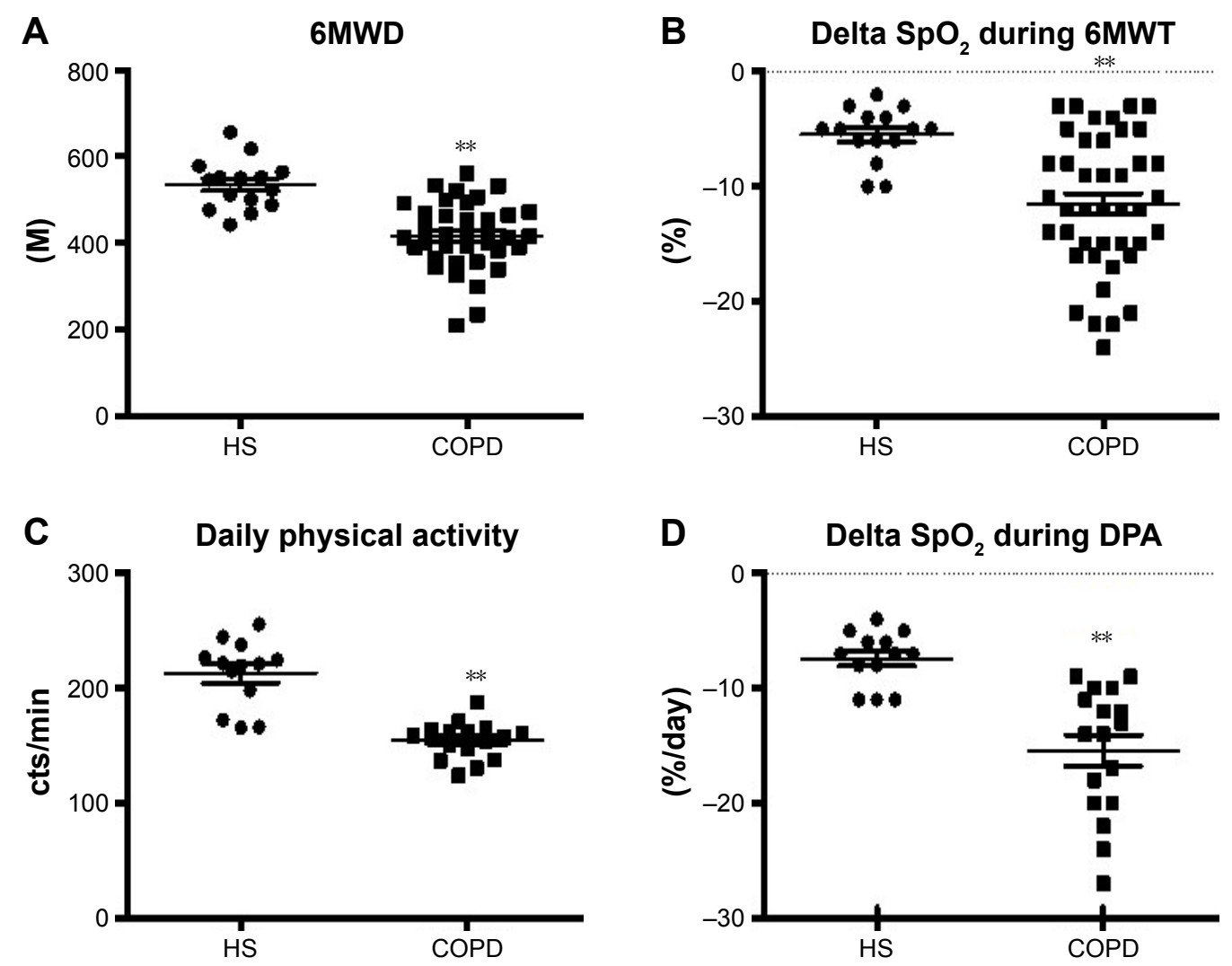

Figure I (A) 6MWD during the 6MWT in healthy subjects and COPD patients. (B) Delta SpO, during the 6MWT in healthy subjects and COPD patients. (C) DPA in healthy subjects and COPD patients. (D) Delta $\mathrm{SPO}_{2}$ during DPA in healthy subjects and COPD patients. $* * P<0.01$ between groups.

Abbreviations: $6 \mathrm{MWD}, 6$ min walking distance; $6 \mathrm{MWT}, 6$ min walking test; DPA, daily physical activity; $\mathrm{HS}$, healthy subject; $\mathrm{SpO}_{2}$, saturation of pulse oxygenation.

correlated with proteasome activity; the BMI, MAC, CC, $\mathrm{FEV}_{1}$, and 6MWD were significantly correlated with protein carbonyl $(r=-0.318, P<0.05 ; r=-0.350, P<0.05 ; r=-0.322$, $P<0.05 ; r=-0.441, P<0.01$; and $r=-0.313, P<0.05$, respectively).

\section{Discussion}

The primary findings of this study are that serum proteasome activities were correlated with DPA in patients with COPD and with delta $\mathrm{SpO}_{2}$ during the 6MWT in HSs, but there was no significant correlation with airflow obstruction severity. In addition, patients with COPD had higher protein carbonyl and proteasome activity than HSs. Finally, this study showed that a reduced 6MWD and lower $\mathrm{SpO}_{2}$ during the 6MWT were the best surrogate markers of inactivity during the daily physical life of COPD patients.

The origin and function of blood proteasomes in patients with COPD are unclear. However, our data showed that

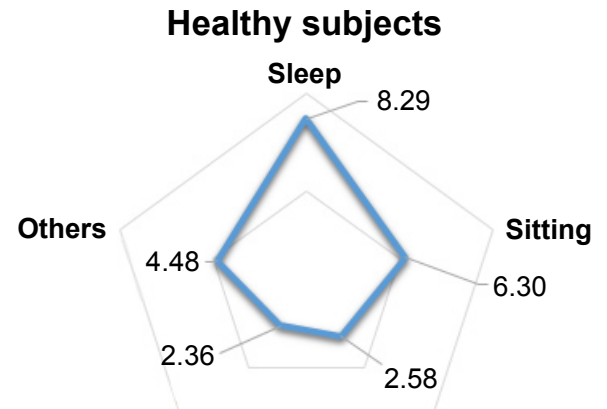

Standing

Walking

\section{COPD patients}

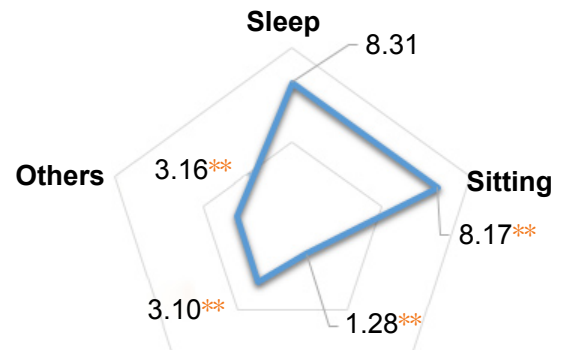

Standing

Walking

Figure 2 Time spent in each of the activities or body positions in healthy subjects and COPD patients during the entire day. Note: $* * P<0.0$ I between groups. 

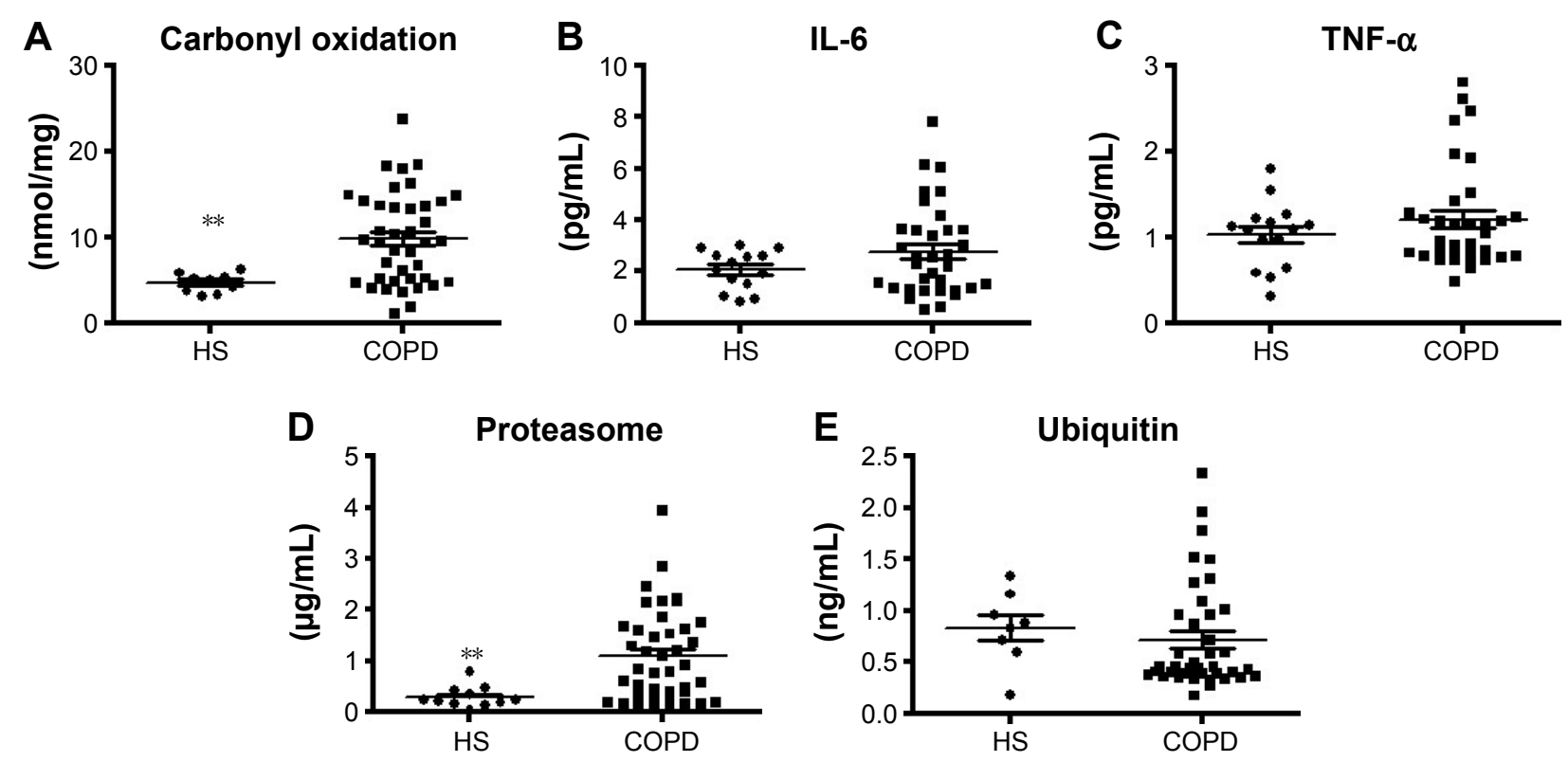

Figure 3 (A) Serum protein carbonyl levels in healthy subjects and subjects with COPD. (B) IL-6 levels in healthy subjects and COPD patients. (C) Serum TNF- $\alpha$ levels in healthy subjects and COPD patients. (D) Serum proteasome activity in healthy subjects and COPD patients. (E) Serum ubiquitin levels in healthy subjects and COPD patients. $* * P<0.0$ I between groups.

Abbreviations: HS, healthy subject; IL-6, interleukin-6; TNF- $\alpha$, tumor necrosis factor- $\alpha$.

COPD patients had higher proteasome activity and lower exercise activity than HSs, and the serum proteasome activity appeared to be correlated with low DPA and delta $\mathrm{SpO}_{2}$.

DPA was observed to be lower in COPD patients than in healthy controls and lower than the proposed international guidelines for physical health maintenance. ${ }^{20} \mathrm{COPD}$ patients spent less than one-third of their time walking and standing, and therefore spent much more time sitting or lying around, while HSs spent more than half of their time walking or standing..$^{21}$ In our study, COPD patients spent $1.28 \mathrm{~h}$ of their time walking and more than one-third of their time sitting or lying down, while HSs spent $2.95 \mathrm{~h}$ of their time walking and $5.28 \mathrm{~h}$, or less than one-third of their time, sitting. The World Health Organization guidelines for physical activity recommend that all adults should undertake at least $2.5 \mathrm{~h}$ of moderate-intensity aerobic activity per week, such as walking, to maintain a healthy lifestyle. In COPD patients, sedentary behaviors are believed to be crucial to the development of skeletal muscle weakness, and resting and exercise muscle metabolism is impaired. ${ }^{22}$

Inflammation in COPD also leads to a protein catabolic state. COPD patients appear to be under a state of continuous

Table 2 Pearson's correlation coefficients $(r)$ of proteasome activity, protein carbonyl, and functional physical activity in subjects

\begin{tabular}{|c|c|c|c|c|c|c|}
\hline \multirow[t]{2}{*}{ Indicator } & \multicolumn{3}{|c|}{ Proteasome activity } & \multicolumn{3}{|c|}{ Protein carbonyl } \\
\hline & Total subjects & HSs & COPD & Total subjects & HSs & COPD \\
\hline \multicolumn{7}{|l|}{ Anthropometric indicator } \\
\hline BMI $\left(\mathrm{kg} / \mathrm{m}^{2}\right)$ & 0.256 & 0.573 & 0.212 & -0.223 & -0.605 & $-0.318^{*}$ \\
\hline $\operatorname{MAC}(\mathrm{cm})$ & 0.004 & 0.032 & -0.012 & $-0.323 *$ & -0.270 & $-0.350^{*}$ \\
\hline$C C(\mathrm{~cm})$ & 0.156 & -0.595 & 0.070 & $-0.340 *$ & $-0.4 \mid 4$ & $-0.322^{*}$ \\
\hline FFMI $\left(\mathrm{kg} / \mathrm{m}^{2}\right)$ & 0.038 & 0.479 & 0.050 & -0.227 & 0.074 & -0.309 \\
\hline $\mathrm{FEV}_{1}$ (\% predicted) & -0.235 & -0.191 & 0.079 & $-0.526 * *$ & 0.582 & $-0.44 I^{* *}$ \\
\hline \multicolumn{7}{|l|}{ Functional physical activity } \\
\hline DPA (counts/min) ${ }^{\mathrm{a}}$ & $-0.529 *$ & 0.264 & $-0.568 *$ & 0.089 & 0.310 & 0.114 \\
\hline Delta $\mathrm{SpO}_{2}(\% / \text { day })^{\mathrm{b}}$ & -0.350 & -0.312 & -0.131 & -0.063 & -0.098 & 0.208 \\
\hline 6MWD (m) & -0.200 & -0.339 & -0.067 & $-0.439 *$ & 0.338 & $-0.313^{*}$ \\
\hline Delta $\mathrm{SpO}_{2}(\%)$ & 0.041 & 0.685 & 0.186 & -0.054 & 0.042 & 0.130 \\
\hline Protein carbonyl (nmol/mg) & 0.098 & -0.459 & 0.016 & - & - & - \\
\hline
\end{tabular}

Notes: ${ }^{2}$ According to DPA subjects (II HSs and 16 COPD patients); ${ }^{b}$ according to the delta $\mathrm{SpO}_{2}$ subjects (II HSs and I6 COPD patients); $* P<0.05$, $* * P<0.0$ I.

Abbreviations: 6MWD, 6 min walking distance; BMI, body mass index; CC, calf circumference; DPA, daily physical activity; FEV second; FFMI, fat-free mass index; $\mathrm{HSs}$, healthy subjects; $\mathrm{MAC}$, mid-arm circumference; $\mathrm{SpO}_{2}$, saturation of pulse oxygenation. 
systemic inflammation, as suggested by high levels of C-reactive protein, oxidative stress, and other proinflammatory mediators. ${ }^{23}$ Our results showed no significant differences in any inflammatory marker between the two groups. Oxidative stress may act as a potential mechanism in the pathogenesis of COPD patients. ${ }^{24}$ Compared to HSs, COPD patients were characterized by increased systemic and pulmonary oxidative stress markers both at rest and those induced by exercise, and this result suggests that healthy control subjects are able to tolerate exercise more effectively than COPD patients. ${ }^{25}$ This study observed higher carbonyl oxidation levels in COPD patients, which were higher than those of HSs. We observed that the levels of protein carbonyl were correlated with the airflow obstruction severity in $\mathrm{FEV}_{1}$; this result is similar to that of a past study, ${ }^{26}$ but there was no correlation with functional physical activity.

\section{Limitations}

This study has some limitations. First, this study has a relatively small sample size, and the study sample was drawn from a single hospital. Therefore, larger sample sizes from different centers are needed to confirm our results. Second, the function and mechanism of circulating proteasomes were not evaluated in this study. Further studies are needed to clarify their function and mechanism. Third, this study involved only $24 \mathrm{~h}$ ambulatory actigraphy and oximetry, and not all HSs and COPD patients had DPA and $\mathrm{SpO}_{2}$ measured. The applicability of these results to longer periods of actigraphy and oximetry requires further investigation. Fourth, inactivity may not only lead to more proteasome activity, but also cachexia, and the associated high proteasome activity may lead to less daily activity. This study design could not establish causal relationships. Finally, most patients referred to this center were male; hence, we could not assess the effect of gender. Further samples are needed to increase female participation.

\section{Conclusion}

Circulating proteasome activities were significantly and negatively correlated with DPA in COPD patients. Our findings suggest that circulating proteasome activity and daily functional activities are related. Further longitudinal observations and exercise interventional studies are required to establish whether this link is causal in nature.

\section{Acknowledgments}

The authors wish to thank the patients and personnel of the hospital unit for their cooperation during the course of this study. The authors wish to thank Ms Yi-Syuan Lin and Mr LuWei Kuo for their technical assistance with this research.

The study was supported by grants from the Taipei Medical University (TMU102-AE1-B45, TMU103-AE1B31) and Taipei Medical University-Shuang Ho Hospital (103TMU-SHH-01-4, 103TMU-SHH-01-2, and 104TMUSHH-24).

\section{Author contributions}

Kang-Yun Lee and Tzu-Tao Chen conceived the idea, designed, carried out the study, and performed the statistical analysis. Ling-Ling Chiang, Hsiao-Chi Chuang, Po-Hao Feng, Wen-Te Liu, and Kuan-Yuan Chen assisted in subject recruiting and helped to carry out the study. Shu-Chuan Ho directed the statistical analysis, data interpretation, and was the main writer of the manuscript. All authors contributed toward data analysis, drafting and revising the paper and agree to be accountable for all aspects of the work. All authors have read and approved the final version of the manuscript for publication.

\section{Disclosure}

The authors report no conflicts of interest in this work.

\section{References}

1. Kiyokawa H, Muro S, Oguma T, et al. Impact of COPD exacerbations on osteoporosis assessed by chest CT scan. COPD. 2012;9(3):235-242.

2. Fischer BM, Pavlisko E, Voynow JA. Pathogenic triad in COPD: oxidative stress, protease-antiprotease imbalance, and inflammation. Int J Chron Obstruct Pulmon Dis. 2011;6:413-421.

3. Mador MJ, Deniz O, Aggarwal A, Kufel TJ. Quadriceps fatigability after single muscle exercise in patients with chronic obstructive pulmonary disease. Am J Respir Crit Care Med. 2003;168:102-108.

4. Gosselink R, Troosters T, Decramer M. Peripheral muscle weakness contributes to exercise limitation in COPD. Am J Respir Crit Care Med. 1996;153:976-980.

5. Baumeister W, Walz J, Zuhl F, Seemuller E. The proteasome: paradigm of a self-compartmentalizing protease. Cell. 1998;92(3):367-380.

6. Ho SC, Hsu MF, Kuo HP, et al. The relationship between anthropometric indicators and walking distance in patients with chronic obstructive pulmonary disease. Int J Chron Obstruct Pulmon Dis. 2015; 10:1857-1862.

7. Koechlin C, Maltais F, Saey D, et al. Hypoxaemia enhances peripheral muscle oxidative stress in chronic obstructive pulmonary disease. Thorax. 2005;60(10):834-841.

8. Caspersen CJ, Powell KE, Christenson GM. Physical activity, exercise, and physical fitness: definitions and distinctions for health-related research. Public Health Rep. 1985;100(2):126-131.

9. Thompson PD, Buchner D, Pina IL, et al. Exercise and physical activity in the prevention and treatment of atherosclerotic cardiovascular disease: a statement from the Council on Clinical Cardiology (Subcommittee on Exercise, Rehabilitation, and Prevention) and the Council on Nutrition, Physical Activity, and Metabolism (Subcommittee on Physical Activity). Circulation. 2003;107(24):3109-3116.

10. Watz H, Waschki B, Boehme C, Claussen M, Meyar T, Magnussen H. Extrapulmonary effects of chronic obstructive pulmonary disease on physical activity: a cross-sectional study. Am J Respir Crit Care Med. 2008;177(7):743-751. 
11. Liu WT, Kuo HP, Liao TH, et al. Low bone mineral density in COPD patients with osteoporosis is related to low daily physical activity and high COPD assessment test scores. Int J Chron Obstruct Pulmon Dis. 2015;10:1737-1744.

12. Garcia-Aymerich J, Lange P, Benet M, Schnohr P, Anto JM. Regular physical activity reduces hospital admission and mortality in chronic obstructive pulmonary disease: a population based cohort study. Thorax. 2006;61(9):772-778.

13. Pitta F, Troosters T, Probst VS, et al. Possíveis conseqüências de não se atingir a mínima atividade física diária recomendada em pacientes com doença pulmonar obstrutiva cronica estável [Potential consequences for stable chronic obstructive pulmonary disease patients who do not get the recommended minimum daily amount of physical activity]. J Bras Pneumol. 2006;32(4):301-308. Portuguese.

14. Garcia-Rio F, Lores V, Mediano O, et al. Daily physical activity in patients with chronic obstructive pulmonary disease is mainly associated with dynamic hyperinflation. Am J Respir Crit Care Med. 2009; 180(6):506-512.

15. de Kam D, Smulders E, Weerdesteyn V, Smits-Engelsman BC. Exercise interventions to reduce fall-related fractures and their risk factors in individuals with low bone density: a systematic review of randomized controlled trials. Osteoporos Int. 2009;20(12):2111-2125.

16. Rabe KF, Hurd S, Anzueto A, et al. Global strategy for the diagnosis, management, and prevention of chronic obstructive pulmonary disease: GOLD executive summary. Am J Respir Crit Care Med. 2007;176(6):532-555.

17. Hsu MF, Ho SC, Kuo HP, Wang JY, Tsai AC. Mini-nutritional assessment (MNA) is useful for assessing the nutritional status of patients with chronic obstructive pulmonary disease: a cross-sectional study. COPD. 2014;11(3):325-332.
18. ATS Committee on Proficiency Standards for Clinical Pulmonary Function Laboratories. ATS statement: guidelines for the six-minute walk test. Am J Respir Crit Care Med. 2002;166(1):111-117.

19. Casanova C, Hernandez MC, Sanchez A, et al. Twenty-four-hour ambulatory oximetry monitoring in COPD patients with moderate hypoxemia. Respir Care. 2006;51(12):1416-1423.

20. Bossenbroek L, de Greef MH, Wempe JB, Krijnen WP, Ten Hacken NH. Daily physical activity in patients with chronic obstructive pulmonary disease: a systematic review. COPD. 2011;8:306-319.

21. Pitta F, Troosters T, Spruit MA, Probst VS, Decramer M, Gosselink R. Characteristics of physical activities in daily life in chronic obstructive pulmonary disease. Am J Respir Crit Care Med. 2005;171(9): 972-977.

22. Engelen MP, Schols AM, Does JD, Gosker HR, Deutz NE, Wounters EF. Exercise-induced lactate increase in relation to muscle substrates in patients with chronic obstructive pulmonary disease. Am J Respir Crit Care Med. 2000;162(5):1697-1704.

23. Bolton CE, Evans M, Ionescu AA, et al. Insulin resistance and inflammation-A furthersystemic complication ofCOPD.COPD.2007;4(2) 121-126.

24. Kirkham PA, Barnes PJ. Oxidative stress in COPD. Chest. 2013;144: 266-273.

25. Pinho RA, Chiesa D, Mezzomo KM, et al. Oxidative stress in chronic obstructive pulmonary disease patients submitted to a rehabilitation program. Respir Med. 2007;101(8):1830-1835.

26. Rahman I, van Schadewijk AA, Crowther AJ, et al. 4-Hydroxy-2 nonenal, a specific lipid peroxidation product, is elevated in lungs of patients with chronic obstructive pulmonary disease. Am J Respir Crit Care Med. 2002;166(4):490-495.
International Journal of COPD

\section{Publish your work in this journal}

The International Journal of COPD is an international, peer-reviewed journal of therapeutics and pharmacology focusing on concise rapid reporting of clinical studies and reviews in COPD. Special focus is given to the pathophysiological processes underlying the disease, intervention programs, patient focused education, and self management protocols.

\section{Dovepress}

This journal is indexed on PubMed Central, MedLine and CAS. The manuscript management system is completely online and includes a very quick and fair peer-review system, which is all easy to use. Visit http://www.dovepress.com/testimonials.php to read real quotes from published authors. 